\title{
Chile como paratexto: el espacio regional en los atlas literarios de los años cuarenta
}

\author{
Chile as a paratext: the regional space \\ in the literary atlases of the $40 \mathrm{~s}$
}

\section{MARIO VERDUGO ARELLANO}

\author{
Universidad de Talca \\ Correo electrónico: verdugoarellano@gmail.com
}

\begin{abstract}
A partir de la equivalencia entre procesos de ecumenización (fenómeno territorial) y actividades descriptivas (fenómeno textual), el artículo indaga en un corpus discursivo cuyo auge habría de producirse en la década del cuarenta, incluyendo autores como Gabriela Mistral, Antonio Roco del Campo, Eduardo Blanco-amor y Benjamín Subercaseaux. Según se observa en este conjunto de atlas literarios, el modelo nacionalizante de espaciamiento va imponiéndose a lo que es percibido como "parte" más o menos fundamental del país - provincias tributarias y permanentemente disponibles-, a través de paratextos que cumplen la función de dar legibilidad y frenar la fragmentación sin control, aun cuando ello no baste para suprimir la emergencia de ambiguas relaciones entre nación y región, entre centro y periferia, entre cada texto de origen y su puesta en libro.
\end{abstract}

Palabras clave: atlas literarios, paratexto, territorio, literatura regional

From the equivalence between ecumenization processes (territorial phenomenon) and descriptive activities (textual phenomenon), the article explores a discursive corpus whose rise would occur in the decade of 1940, including authors such as Gabriela Mistral, Antonio Roco del Campo, Eduardo Blanco-Amor and Benjamín Subercaseaux. As noted in this set of literary atlases, the nationalizing spacing model starts prevailing in what is perceived as a more or less fundamental "part" of the country -tributary and permanently available provinces-, through paratexts that fulfill the function of giving readability and curb uncontrolled fragmentation, even when this is not sufficient to suppress the emergence of ambiguous relations between the nation and the regions, between the center and the periphery, between each source text and its publication as a book.

Key words: territory and nation, literary atlases, paratext, regional literature. 


\section{INTRODUCCIÓN}

Hacia 1945, el Estado de Chile se empeña en una vasta faena de prospección y catastro. Bajo una lógica geoeconómica que implica conocer cabalmente sus recursos naturales y humanos, este designio tiene como expresión privilegiada a las iniciativas de la Corfo (Corporación de Fomento de la Producción), que buscará subsanar la carencia de investigaciones sistemáticas sobre el territorio y sugerir vías de aprovechamiento en aras del desarrollo, ya se tratase de infraestructuras, de paisajes con potencial turístico, de yacimientos petrolíferos o, por cierto, de personas, etnias y comunidades periféricas. Concretado en volúmenes que no acaban de publicarse sino hasta varios años más tarde, el proyecto se encuentra atravesado por una evidente racionalidad técnica, una marcada preponderancia de lo físico, donde por lo general la población es concebida en términos de mano de obra y la naturaleza suele reducirse a depósito de insumos explotables (Arenas y Núnez 2013: XXIX). Es desde luego un sesgo economicista y antropocéntrico -aquella bestia negra de los actuales green studies - lo que orienta la mirada "hacia adentro" y señala además el valor de las regiones en el marco omniabarcador de la nación.

En ningún caso el impulso por escrutar el país podría pensarse privativo de ese momento histórico. Ciclos exploratorios previos se dieron durante el siglo XIX y aun en la Colonia, pero el punto es que los cuarenta parecen constituir uno de los periodos clave en la historia territorial chilena, en la autoconciencia nacional y, asimismo, en la institucionalización de la geografía como disciplina. La década en cuestión es significativa para los tres niveles. Como lo plantea Andrés Estefane (2015), a la sazón tienden a consumarse las transiciones del "Chile nuevo", de modo que el número de provincias se ha casi triplicado, el control estatal ha querido extenderse hasta la Antártica y por primera vez hay más habitantes en las ciudades que en los campos. Sin gozar todavía de una clara legitimidad científica ni de una vocación pública consolidada, las prácticas geográficas se debaten por su parte entre una línea de índole castrense y otra más bien universitaria, incipiente y, en lo sucesivo, tan cercana a las humanidades como a los propósitos industrializadores que la Corfo implementa bajo el mandato del Frente Popular (Quiroz y Narváez 2014: 32). Si en ambas líneas se multiplican los hitos epocales (creación de cátedras y revistas, por ejemplo), una tercera corriente de reflexión y documentación sobre el territorio se manifiesta simultáneamente y con notoria intensidad. A tal corriente -que no proviene de las academias militares y tampoco de los claustros civiles, pero que sí estila reproducir a grandes rasgos la misma mirada catastral y prospectiva- es a la que dedicaremos los próximos párrafos. Su estatuto disciplinar no siempre resulta indudable: literatura sobre todo, según su propia percepción; y a la vez una encarnación paralela o propulsora de la emergente ciencia geográfica (Arenas y Núńez 2013: XXXI); e inclusive una especie de crisis epistemológica avant la lettre, un prototipo de lo que sólo en fecha muy posterior se tendrá como "crítica radical del espacio" (Quiroz y Narváez 2014: 38).

Alrededor de 1940, en efecto, se advierte un extraordinario auge de la tematización literaria con voluntad chilenizante. En poesía, se escriben o se publican "Canto general de 
Chile", de Neruda; Epopeya de las comidas y las bebidas de Chile, de Pablo de Rokha; y Poema de Chile, de Gabriela Mistral ${ }^{1}$. Dos novelas consideradas epónimas del criollismo pasan por imprenta: Frontera, de Luis Durand (1949); y Gran señor y rajadiablos, de Eduardo Barrios (1948). Y Durand reúne además sus artículos breves en Presencia de Chile (1942) y Alma y cuerpo de Chile (1947). Con un catálogo como este sobraría para rebatir cualquier impresión de retroceso en el uso de los recursos intranacionales como materia de ejercicio poético, novelístico o ensayístico. Pero acaso el fenómeno más saliente sea el de lo que acá llamaremos atlas literarios; un fenómeno al que, por supuesto, varios de los títulos antedichos harían aportes. El empadronamiento libresco del territorio, ya pedido por Lastarria un siglo atrás, aunque formalizado en los albores del XX por críticos como Armando Donoso, alcanza un grado tal de sofisticación que favorece la producción de 'colecciones de mapeos verbales más o menos exhaustivos'. Desde 1939, con Panorama y color de Chile, de Antonio Roco del Campo, pareciera que se contase ya con la cantidad adecuada de datos para pergeñar una visión total de la nacionalidad. El país puede ser conocido por completo -o casi- si se recurre a los libros que han reflejado cada uno de sus tramos. Asumiendo, sin embargo, que en el presente no correspondería suscribir de manera aproblemática el punto de vista entonces compartido por Roco, Durand, Latorre, Benjamín Subercaseaux y tantos otros (es decir, que las regiones se prestan naturalmente a una representación de orden nacional), nos interesa mostrar de qué forma y desde qué lugares de enunciación se chileniza; cuáles son los procedimientos específicos que convierten a un texto cualquiera -adscribible a escalas diversas- en un texto chileno; y qué secuelas identitarias, no exentas de violencia simbólica, comportan esos procedimientos para el espacio referencial en trance de integración, exhibición y explotación.

Nuestra propuesta es que la nación no termina de instaurarse en los atlas sino a través de una serie de dispositivos auxiliares (títulos, prólogos, elementos icónicos, solapas, índices y encabezados explicativos), insertos desde un centro que administra los espacios textuales y extratextuales, y que puede hacerse o no explícito. En el plano del mundo mapeado, el paratexto cumple un papel geopolítico importantísimo, ecumenizando, segando, enajenando y unificando, mientras que en el nivel del libro o la página su función da pábulo a visibles paradojas, pues el centro administrador actúa allí desde la periferia, desde lo no principal, desde aquellos elementos que se estiman subsidiarios y a menudo prescindibles.

\footnotetext{
Poema de Chile se publica en 1967, pero como afirma Soledad Falabella (2003: 7), comienza a escribirse en los cuarenta. El prólogo de Doris Dana a la primera edición lo define como "un viaje de ella a lo largo de su país, de norte a sur, en compañía del niño y del huemul”. La Epopeya aparece originalmente en 1949 sin la indicación paratextual de nacionalidad y como parte de Carta magna de América, con el subtítulo “Teogonía y cosmología del libro de cocina (Ensueńo del infierno)”, mientras que el texto nerudiano se incluye en el Canto general de 1950, aunque algunos de sus poemas están fechados en 1939, 1941 y 1942.
} 


\section{NACIÓN Y SINÉCDOQUE}

Roco subtitula su Panorama como "antología literario-descriptiva del paisaje y las costumbres nacionales", y en el prólogo esclarece cuál es el telos que orienta su trabajo y el de sus colegas: "Traspuesto el umbral del siglo, el nacionalismo asume formalmente las características de una tendencia preponderante, capaz de supeditar a toda obra" (1939: 13). Para Roco, Chile presenta un carácter fragmentario pero no heterogéneo, de modo que cada zona concurre a la antología con unas cualidades definidas y diferenciales sólo en la medida en que contribuyen a enterar una totalidad variopinta. Esta fragmentariedad queda refrendada deliberadamente en la forma de la exposición, hecha de piezas cortas que describen el norte, el centro y el sur de acuerdo a la perspectiva del editor-antólogo, o de los poetas y novelistas que se han dignado a localizar sus creaciones. Hay en el Panorama, claro está, textos donde el valor sinecdóquico de un pueblo o una provincia viene dispuesto antes de cualquier intervención editorial, como la crónica en que Luis Enrique Délano pone en manos de los feligreses de Olmué una inequívoca bandera tricolor (Roco 1939: 279), pero en decenas de casos - la mayoría, a decir verdad- no existe referencia alguna que permita pasar de la parte al todo, salvo que la lectura obedezca unas instrucciones paratextuales agregadas a posteriori y en virtud de agentes distintos al autor seleccionado: "Romance a Talca", de Torres Rioseco, es un poema cuya chilenidad no podría ser establecida sin auxilio del título o el índice del libro, así como "Pichamán”, de Leoncio Guerrero, carece de alusiones geográficas que vayan más allá de aquel espacio recoleto. Algo similar ocurre con "Yerbas Buenas", de Max Jara, o "Perquilenco", de Lagos Lisboa, donde el rol abastecedor de esas imágenes -su representatividad con arreglo a otra escala- depende igualmente de un mensaje secundario.

A los textos circunscritos a lo local deben sumarse los que apuntan a contactos supranacionales (Salvador Reyes bosquejando una Antofagasta unida culturalmente con Bolivia y comercialmente con Hamburgo y Nueva York, pero no con Chile), los que de hecho pasan por alto los reclamos de soberanía (Pierre Loti sobre Isla de Pascua), y los que están mediados por un vocabulario genérico, desprovisto de notaciones endémicas (como las carretas y paisajes campesinos de Magallanes Moure). La siega de territorios se patentiza como un anclaje o un énfasis externo, peritextual ${ }^{2}$, de cuyo posicionamiento metropolitano es fácil tomar nota si se ponderan no sólo los antecedentes materiales más obvios (una imprenta con sede en Santiago), sino también las coordenadas, las direcciones y las distancias reveladas por Roco una y otra vez: qué ciudades se juzgan sureñas o nortinas, el apartamiento en que vive Cruchaga Santa María (habitante de San Bernardo), o el mérito que le cabe a Julio Barrenechea por visitar Monte Patria, "pueblo de mínima significación geográfica”

$2 \quad$ Maite Alvarado (1994: 29-30), basándose en los planteamientos de Genette, distingue el peritexto del epitexto, ya se trate de elementos paratextuales que rodean el texto dentro de los límites del libro (peritexto) o fuera del libro (epitexto), entre los cuales se hallan los discursos que la editorial despliega con miras a la promoción y venta de un libro. Debido al ocasional empleo de epitextos, se ha optado por privilegiar acá el uso de la noción más general. 
(Roco 1939: 143). La centralidad rebasa por lo tanto al mero centro lingǘstico de la deixis de referencia. El sistema de coordenadas hace coincidir a los dos actantes de la enunciación con sujetos que moran en un mismo lugar, de suerte que parece estar produciéndose una comunicación entre coterráneos de la metrópoli. Se edita y se lee, por ende, en un mismo espacio originador que delimita la elección de los deícticos.

Por lo común laudatoria y volcada a la extracción de suministros estéticos, la apreciación de Valparaíso, Andacollo o Chiloé se funda en una concepción de lo periférico como indiscutible fuente de aprovisionamiento. Dicha concepción afecta en primera instancia a los contenidos regionales que se antologan, y correlativamente a unos textos ajenos de los que no hace falta declarar nunca la procedencia bibliográfica. Es menos un desliz filológico que la naturalización del nacionalismo como horizonte literario -esa "intensiva aspiración unitaria”, a decir de Roco en su prólogo (1939: 14)-, lo que explica este modus operandi, resaltado por lo demás en los prolegómenos que firma Editorial Ercilla: "Roco ha cogido de cada uno su flor [...] Despojando a los cronistas antiguos, a los viajeros atentos, a los mismos poetas de cuanto en ellos trasciende a pedestrismo [...] alquitarando de todos los libros, libando de volúmenes viejos y nuevos, lo más selecto que da la miel misma de Chile" (Roco 1939: 3).

Hablamos acá de regiones o localidades poniendo entre paréntesis la probable diferenciación que pudiese haber entre ambas categorías ${ }^{3}$. El factor compartido, bajo la mirada de quienes confeccionan los atlas, es la pertenencia a un extendido hinterland o periferia subnacional, que se delinea en función de su tributariedad simbólica y económica respecto del núcleo de la nación, vale decir, de la metrópoli desde donde se sale en busca y en donde se acopian los tesoros de Chile y la chilenidad. Regionales son los espacios que Mariano Latorre y Gabriela Mistral denominan con los rótulos de "rincón" y "patria chica". Los Recados mistralianos contienen una "Geografía humana de Chile", de 1939, cuya trabazón se apoya en tres órdenes de relieve: el "mítico" del desierto, el "clásico" del Valle Central y el "romántico" de los archipiélagos sureños. Latorre, en tanto, proporciona dos colecciones ad hoc, una que funge como balance cartográfico de sus propias temáticas (Chile, pais de rincones), y otra que a la manera de Roco combina descripciones personales con un canon nacional regionalizado (La literatura de Chile). La primera colección, de 1947, agrupa cuentos de acuerdo a un recorrido que es casi siempre norte-sur, desde el vapor caletero que zarpa de Tacna y hasta el vetusto pontón fondeado en Punta Arenas. Y La literatura de Chile, de 1941, es una suma de conferencias que pretende organizar un abigarrado corpus a partir de los lugares referidos o el origen regional de los autores, postulando membretes como "novela de la provincia", "poetas del mar" o "Valparaíso y sus intérpretes". Tanto en el rincón como en la patria chica persisten la sinécdoque región-nación

\footnotetext{
3 A la categoría de espacio regional, de ese modo, integramos entidades de muy disímil envergadura, pero que pueden describirse, y metadescribirse, de acuerdo a su común percepción como partes no metropolitanas del territorio de Chile. Sólo bajo esta identificación corriente parece dable hacer caso omiso de las múltiples evocaciones que tolera el término región en las distintas disciplinas.
} 
y la índole preeminente y configuradora del paratexto chilenizante. Merced al consenso que normaliza un modo correcto de ver y representar a los paisajes y sus moradores, la periferia vuelve a someterse a un tipo de visión específica y, se diría, no necesariamente ineluctable.

Al prologar su Chile, país de rincones, Latorre afirma que "la multiplicidad es el carácter del paisaje chileno", al grado en que se torna factible reconocer "siete países que, periódicamente, convergen a la capital", haciéndose entonces inapropiado el querer captar su variada fisonomía en una sola obra (Latorre 1983: 16-17). A juicio de Latorre, la nación se resume en el rincón, el todo está en la parte, y la tarea del escritor radica justamente en el conocimiento de esos rincones múltiples. La literatura se asume como deber, se clasifica y se legitima únicamente si se localiza y nacionaliza. El fundamento de la actividad literaria no es otro que el espacio: espacio nacional como manufactura, y espacio regional como materia prima. Tal fundamento posibilita una sistematización retrospectiva del corpus chileno y al mismo tiempo un ejercicio prospectivo para los poetas y narradores del país. Por un lado, los textos previos pueden barajarse según el rincón que tematizan; y por el otro, las futuras invenciones ficcionales tendrán como objetivo a la saturación de espacios vírgenes de literatura. En aquellas conferencias dictadas en Buenos Aires, Latorre ordena toda la producción literaria de Chile según unos temas y unas raigambres mayoritariamente espaciales, esto es, conforme al espacio empírico en que cada texto y cada autor se arrinconan. El topocentrismo podría tener esta vez una justificación contingente: en principio se está hablando ante un auditorio extranjero, y el atlas se inscribe en una colección donde también figuran panoramas peruanos, colombianos y uruguayos, pero Latorre no se cansa de recalcar en el prólogo que la literatura de un país es en todos los casos inaccesible de no mediar una síntesis geográfica ${ }^{4}$.

La confluencia de Latorre y Mistral puede corroborarse con ayuda de otro acápite de los Recados contando a Chile, donde la poeta reafirma el carácter transitivo del espacio regional al que estima conditio sine qua non de la emoción patriótica: "soy, como ustedes, una regionalista de mirada y de entendimiento, una enamorada de la 'patria chiquita', que sirve y aúpa a la grande" (Mistral 1957: 126). Se diría que el "Regionalismo" de Mistral (título del acápite que empleamos como epitexto) arranca de lo que Alain Roger llama función monádica, la capacidad de una parte quintaesenciada para concentrar lo máximo en lo mínimo, expresando el todo por sinécdoque, en una mónada, un paradigma o ápice de materia (Roger 2007: 37-43). "En geografía como en amor -añade la autora de Tala-, el que no ama minuciosamente, virtud a virtud y facción a facción, el atolondrado, que suele ser un vanidosillo, que mira conjuntos kilométricos y no conoce y saborea detalles, ni ve, ni entiende, ni ama tampoco" (Mistral 1957: 126). Dichas facciones constituyen la base de la identidad chilena, un primer peldaño que en ningún caso se ensimisma, sino que se redirige inevitablemente a lo nacional. Son, por cierto, mónadas virtuosas, facciones loables, pero siempre a partir de su relación con el espacio de mayor magnitud.

\footnotetext{
4 La primera edición de Chile, país de rincones -quede dicho en beneficio de esta función noticiera para públicos extranjeros- fue publicada también en una editorial argentina: Espasa Calpe.
} 
En términos narratológicos y especialmente en lo que concierne al análisis de lo descriptivo, el rincón y la patria chica corresponden al detalle enmarcado por el pantónimo "Chile". Las mónadas no se encuentran a la deriva, ni se nombran o se articulan de acuerdo a un principio de inmanencia. Su aparición en los atlas responde a una filiación semántica común, y a un sistema de jerarquizaciones internas que las subordina a una visión de conjunto. El detalle paradigmático no se lee aislado, por cuanto existe un tema más abarcador que imanta las partes y las pone en órbita. Como señala Pimentel (2001: 23), lo propio de la descripción es su tendencia expansiva, el despliegue de particularidades y atributos, la lista de predicados cuya potencial dispersión es evitada a través de la permanencia léxica del tema. En los atlas de los años cuarenta, los espacios periféricos conforman el cuerpo de este pantónimo o núcleo temático que acostumbra recuperarse mediante diversas clases de paratextos. Así opera Latorre al catalogar sus relatos sobre "el norte", "la selva" o "el nuevo sur", y así opera también Nicomedes Guzmán cuando reúne una cincuentena de textos sobre regiones bajo el título de Autorretrato de Chile. Si Latorre hace de la virtual inagotabilidad temática un programa de trabajo para sí mismo y para la literatura de la nación en general, exhortando a los escritores para que coadyuven sin descanso a lo que vendría a significar la expansión del pantónimo, Guzmán procede a reunir tales contribuciones individuales en repertorios de incontrovertible adscripción nacionalista: el citado Autorretrato, donde los distintos "paisajes quieren concurrir y aunarse con alto propósito humano y literario" (el de hacer sus aportes monádicos a "una gran novela nacional”, Guzmán 1974:19); o los párrafos introductorios a la Colección La Honda, que en la misma década procura revelar "una lumbre definitiva" sobre el carácter chileno, "hondo y audaz", por medio de libros que irán mostrando las distintas facetas de lo criollo, los rasgos idiosincráticos del "norte chico", de los “ambientes pampinos” o del "sur más lejano de la patria” (Guzmán 1945: 7). La Honda constaría al fin y al cabo de doce volúmenes, en cada uno de los cuales Guzmán oficiaría como prologuista encargado de nacionalizar - de nuevo paratextualmente- las historias regionales suministradas por Mario Bahamonde, Reinaldo Lomboy, Óscar Castro o Guillermo Valenzuela. Aunque con frecuencia en esas entradas el lugar de enunciación es un apunte tácito, a veces también tiende a transparentarse, como cuando Guzmán alaba el quehacer de los novelistas que se dedican a "encaminarnos" por una geografía desconocida y a "noticiarnos" de sus remotas realidades (Guzmán: 1946: 7; 1945: 8). La periferia se disgrega en paradigmas de chilenidad y a la vez se vuelve objeto de un desarrollo sintagmático, que gracias a compilaciones como La Honda va convirtiéndose en ecúmene y registro legible. Maniobrando como un dilatado sondeo, los atlas procuran rellenar claros en el mapa y para ello recogen informaciones precisas en las áreas omitidas y en los extremos del territorio, valiéndose de escritores-baqueanos que se internan tierra adentro a la pesquisa de nuevos insumos nacionalizables. Hay aún, entre el núcleo capitalino y las fronteras, una vasta tierra incógnita, y tal es la novedad que el impulso ecuménico, en palabras del propio Guzmán (1945: 7), "ha traído al conocimiento de Chile". 


\section{Centralidades y Recorridos}

De una conversación con Gabriela Mistral, según se proclama en la solapa rubricada por Editorial Exit, nace la idea de Chile: tierra y destino, una voluminosa antología que recopila textos de astrónomos, climatólogos, educadores y economistas, junto con escritores y críticos como Domingo Melfi, Carlos Barella, Alberto Baeza Flores, Edgardo Garrido Merino y la mentada poeta elquina. Al igual que en otros atlas, las setecientas páginas estructuradas por Francisco Méndez presumen de un alcance inaugural, pionero en ese ámbito y ese formato, desentendiéndose de las convergentes intentonas que para entonces, 1948, habían puesto en práctica Roco del Campo y varios más. El paratexto es nuevamente el dispositivo pragmático que consagra la apropiación correlativa de discursos y territorios. Título, solapa, índice y prólogo son los principales soportes de la unidad en sentido doble: como libro unitario y como nación unitaria. No obstante, en esta oportunidad puede aseverarse que la naturalizada integración de las partes al todo cuenta con certificaciones recurrentes al interior mismo de cada texto. Rara vez se echa en falta el pantónimo, pues "Chile" no deja de estar presente cuando Carlos Keller aborda las costumbres chilotas o cuando Garrido tipifica la psicología de los héroes rurales.

Dos variables a sopesar en Chile: tierra y destino dicen relación con la direccionalidad de los recorridos y con la limitada gravitación que la literatura exhibe dentro del atlas. A juzgar por los índices de Méndez, Roco, Mistral, Latorre et alia, la creencia de que el país se recorre de norte a sur parece vivirse con tanta naturalidad como la convicción de que Chile se arma a expensas de los recursos provincianos. El segundo aspecto — sólo un puñado de escritores entre conspicuos y mucho más numerosos científicos- podría servir para cuestionar la genuina literariedad de la antología, pero en definitiva es lo literario, la carga retórica nada escasa de imágenes míticas y antropomorfizantes (Chile como regalo de los dioses, o como un cuerpo cuyas piernas juegan con los hielos del polo), lo que predomina desde las advertencias paratextuales y ciertamente transforma la esperable ortodoxia académica en ensayos divulgativos para "las nuevas generaciones" (Méndez 1948: 7).

De norte a sur, ya está dicho, se compaginan los atlas de Latorre, Gabriela Mistral, Antonio Roco del Campo, Francisco Méndez y Nicomedes Guzmán. Hegemónico como se antoja por su reincidencia, este modo de practicar los recorridos y de disponer los mapas dista de ser monolítico, como lo veremos más abajo en Blanco-amor y De Rokha. La obra de Benjamín Subercaseaux resulta ilustrativa por lo que atañe a esa longitudinalidad dominante aunque no unívoca, y lo es también en lo que toca al papel desempeñado por el espacio metropolitano5. En Chile o una loca geografía-texto repetidamente aludido

\footnotetext{
$5 \quad$ Ciertamente, la nacionalidad en Chile o una loca geografia rebasa el paratexto para ir desparramándose también en el cuerpo textual principal. Aun en casos como este, el paratexto comporta un refuerzo, un énfasis, que frena la oscilación hacia niveles de representación más acotados. Así lo refrenda el autor: "Porque esta es la verdad y el sabor de Chile: un mismo hombre reaccionando frente a 'países' diversos que son Chile y que no lo son, ya que, instintivamente, ponemos el acento nacional en uno de ellos, y según sea el que elegimos como padrón, aparece un Chile diverso y susceptible de las más variadas combinaciones. En realidad, hay tantos 'Chiles' como chilenos repartidos por su vasto territorio" (Subercaseaux 1946: 263).
} 
como contrapunto de los proyectos de la Corfo y de la disciplina geográfica en fase de institucionalización (Quiroz y Narváez 2014: 42; Arenas y Núñez 2013: XXXI)-, Subercaseaux concede a Santiago una cantidad de páginas superior a la de cualquiera otra ciudad del país, y sus descripciones de la metrópoli parten por reconocer su condición de eje desde el cual todo se vislumbra exótico. Santiago es de hecho "el corazón palpitante de esta tierra de desiertos montańas y fiordos" (172), el sitio donde los sujetos periféricos van a formarse, "a recibir la enseñanza en las Ciencias o el vivir" (141). Se está sin embargo ante una centralidad todavía mal bosquejada, un territorio igual de difuso que el resto de Chile. El núcleo geopolítico aún "trata de saber lo que es", y aguarda "una interpretación que vaya más allá del hábito y de la visión de costumbre" (135). De ahí que la capital, a despecho de su importancia ya decretada, venga a ser conducida a los ámbitos de lo exhibible y lo incorporable. Santiago, en el planteamiento de Subercaseaux, funciona como mónada, como una parte representativa más, y a eso colaboran tanto su integración vertical a la geografía chilena (coordenada intermedia entre el norte "heroico" y el sur "ladino") como su disociación en microterritorios, identidades barriales, rincones urbanos que en resumidas cuentas son como "pequeñas aldeas" (163).

La cuestión de los recorridos puede observarse siguiendo de principio a fin esto que Mistral designara como un "ensayo geográfico" (Subercaseaux 1946: 13). Tras una introducción histórica, Subercaseaux empieza por Arica y va encaminándose por "las mañanas tranquilas", "la muralla nevada" y los "espejos azules" hasta arribar a Navarino, finis terrae. Sólo muy de tarde en tarde se desvía de ese trayecto fronterizado por un "Alfa" y un "Omega" (404), y al que sería recomendable leer teniendo a la mano "la carta correspondiente": un mapa "donde se perfilaran los ríos, los montes y las ciudades" (69). Una metrópoli provincianizada, por decirlo así, y un recorrido norte-sur que se emprende de modo normalizado, con arreglo a los documentos cartográficos de uso corriente, han de contarse entre las constantes de los atlas que a la fecha se multiplican. Las dos tendrían poderosos efectos de sentido, porque si el rincón santiaguino se entromete con el privilegio centralista, encubriéndolo o desestabilizándolo, la direccionalidad hegemónica sirve de fondo a unas prácticas anómalas, generadas desde puntos de vista perceptiblemente locales o internacionales.

Profusa en el empleo de topónimos, la rokhiana Epopeya de las comidas y las bebidas de Chile complejiza y -cabría añadir- distorsiona el recorrido usual de los atlas literarios. Si bien no habría motivo para poner tela de juicio el estatuto nacional anunciado por el paratexto ${ }^{6}$ y enseguida ratificado por copiosas menciones poemáticas a banderas chilenas, rotos chilenos, pasteles, uvas y quesos chilenos, la Epopeya puede ir de sur a norte, de la ciudad al campo, de San Felipe a Las Condes y luego a Chillán sin que se advierta atributo alguno de centralidad, ni tampoco indicaciones de un trayecto obligado. No se trata aquí, en todo caso, de la dirección longitudinal con que los modernos sistemas de comunicación

\footnotetext{
6 Como se indicó más atrás, el pantónimo Chile no figura en la edición original, cuyo título es "Teogonía y cosmología del libro de cocina (Ensueño del infierno)".
} 
y transporte marcan la experiencia republicana (Núnez 2013), sino de un desplazamiento a la ventura, random, que responde únicamente a las apetencias del hablante. En su configuración espacial, esta anomalía se reitera en el texto recopilatorio que el español Eduardo Blanco-amor publica a inicios de la década siguiente. Los capítulos de su Chile a la vista se suceden en razón de un criterio multidireccional, a partir de las notas periodísticas que el autor había redactado como cronista viajero, y adicionando después los artículos que produjese ex profeso, ya encomendado por la Editorial del Pacífico. "Contar un país desde su capital -escribe Blanco-amor-, es un poco tomar el rábano por las hojas", de forma que sus viajes prefiere llevarlos a cabo "desde Punta Arenas a Arica", sin la guía de "ningún plan o determinismo geográfico", y con "todos los cacheos laterales que me fue posible hacer" (11). Aún cuando el índice definitivo desemboca en una referencia magallánica, con lo que pareciera resignarse otra vez a la orientación consabida, lo mismo el libro que el periplo buscan describir más bien un "trazado cruciforme", sin descuidar "los brazos" donde radican la "aventura, el deslumbramiento y la maravilla" (11). No importando establecer si lo anómalo se debe a su forastería autoral, el asunto es que Chile a la vista se aparta o por lo menos deja en suspenso la modalidad del anclaje nacionalizante. Junto con las inversiones y lateralizaciones del recorrido norte-sur, habría que considerar el contraste entre la exhaustividad reivindicada por buena parte de los atlas y el sello de incompletitud que los paratextos notifican en este caso particular ("anotaciones volanderas", "caza intuitiva", "rápido gesto venatorio", 12), amén del tipo de relación que Eduardo Blanco-amor estipula con sus destinatarios potenciales. Si los escritores-baqueanos de Roco y Guzmán "encaminaban" o "noticiaban" a un público presumiblemente capitalino y al amparo de una teleología nacional incontestable, Blanco-amor piensa primero en enseñar sus cuadros regionales a los propios retratados (12), incluso si esos cuadros critican las negligencias estatales o el "tufillo de idioma escolar", postizo y algo belicoso, que se desprende de una bandera chilena en el Morro de Arica (303).

\section{EstétiCa y PAISAJE}

El afán utilitario que preside los catastros del Estado en los cuarenta, aquel desarrollismo menesteroso de conocimiento territorial fidedigno, se replica sólo a medias en los atlas en comento. Las "anotaciones volanderas" de Blanco-amor se sitúan al extremo de una modalidad de escrutinio donde lo útil es remodelado a cada instante por lo estético. En Chile a la vista se profesa antes que todo "el placer de la visión", según lo instruye un epígrafe de Ortega y Gasset, mientras que Benjamín Subercaseaux cimenta su loca geografía nada menos que en cuatro variantes hedónicas: "placer del Arte, placer del espíritu, placer del vivir [...] placer de ser chileno" (1946: 27). El hedonismo suele engranar con un repudio a las cortapisas de la ciencia y en especial de la geografía académica, que el español opone al "tránsito avizor del poeta" (12) y que Subercaseaux empareja con "cosas complicadas y desagradables" (27). Son éstas, dicho sea de paso, persuasiones no reñidas con el interés publicitario o 
autocelebratorio que es frecuente en los paratextos ${ }^{7}$, ni en el fondo antagónicas en cuanto al anhelo de chilenización productiva. Trascendiendo las vicisitudes del campo artístico y específicamente literario, la estética en buena parte de los atlas continúa siendo un usufructo, puesto que la belleza de los rincones -esa singularidad de las provincias incorporadas al ecúmene- viene a utilizarse como factor energético, favorable al reclutamiento colectivo de la sensibilidad. Como lo plantea Mandoki (2007: 26), los objetos estéticos llegan a ser en el Estado moderno preciados agentes de cohesión nacional, un "combustible" indispensable para la reproducción de una identidad que de lo contrario resultaría demasiado abstracta. Y quizá sea ello lo que explique una de las demandas epocales de Mariano Latorre: no evaluar novelas conforme a su calidad intrínseca, sino contabilizando los espacios que muestran e integran, es decir, en función del "acopio de observaciones originales sobre zonas no tocadas anteriormente por los artistas" (Latorre 1953: 52-53).

Los atlas representan el epítome, la evidencia más palmaria de cómo la literatura chilena concibe el territorio durante la primera mitad del siglo veinte. La preponderancia nacionalista que Antonio Roco ve campear una vez traspuesto el umbral del novecientos, y que en general coincide con lo que se ha dado en llamar criollismo, reasoma en proyectos individuales y en diversos llamamientos a escribir con sentido de chilenidad y espíritu de cuerpo. Todo ese nacionalismo criollista trasunta el anhelo de generar un atlas lo más completo posible, y así lo atestiguan los arqueos y programas de Latorre, Domingo Melfi y Armando Donoso. "¿Y Chile? -escribe Latorre en su Autobiografía de una vocación- ¿No

\footnotetext{
Amén de los objetivos comerciales que parecen inherentes a los paratextos de índole editorial (Alvarado 1994: 27), abunda en los atlas literarios un afán de testimoniar el éxito alcanzado por las respectivas tiradas. Blanco-amor, por ejemplo, se felicita en la segunda edición de Chile a la vista por haber obtenido una "efusión epistolar y hasta una reluciente condecoración del Gobierno", además de agotar la primera edición en pocas semanas, récord "sorprendente al no tratarse de un folletón policial, de un manual sexológico o de una diatriba contra la URSS" (1952: 19-20). "El público lector -afirma por su lado Benjamín Subercaseaux (1946: 31) - ha dispensado a esta 'Geografía' una acogida sin precedentes en nuestra industria editorial [...] Es verdad que he tenido en otros tiempos algunos éxitos de crítica, pero debo confesar que ellos no se vieron nunca secundados, como ahora, por un éxito de librería”. A despecho de la verificabilidad cuantitativa de tales parabienes, la década del cuarenta habría de estar en el quid de lo que Bernardo Subercaseaux (1993: 144) llama "la época de oro del libro en Chile", un periodo de fuerte expansión editorial entre cuyos factores se cuentan la mesocratización de la sociedad, la valoración del libro como símbolo de estatus y el proceso también expansivo de la educación. En cualquier caso, esta belle époque no podría atribuirse de buenas a primeras al modelo de sustitución de importaciones, dado que "no hubo ni un rol activo por parte del Estado, ni menos una política de fomento o una legislación proteccionista y sectorial específica” (Subercaseaux 1993: 131).
}

$8 \quad$ No hemos ahondado esta vez en la significación de los paratextos icónicos, o sea, en la gráfica y las ilustraciones como elementos "que se engloban en la composición y ponen el acento en lo perceptivo" (Alvarado 1994: 28). Valga anotar, no obstante, que los atlas suelen incluir -en sus portadas y páginas interiores-imágenes de mapas, emblemas chilenos (banderas o estrellas solitarias) y símbolos cartográficos como brújulas y compases, además de retratos de escritores-baqueanos sobre fondos paisajísticos. El territorio regional/nacional viene a ser abarcado por los profesionales de la palabra, en el marco de esa "decoración cartográfica" a la que no resulta conveniente leer como un mero "ejercicio estético marginal", por cuanto en ella se juegan también formas de apropiación, estereotipia y refuerzo ideológico (Harley 2005: 103-104). 
existía Chile? ¿No eran dignos de ser héroes novelescos los pescadores del Maule y otras regiones? ¿Y nuestros paisajes con la novedad de sus selvas, de sus ríos indómitos y sus ventisqueros?" (Latorre 1953: 31). De acuerdo al autor de Zurzulita, el país atraviesa un periodo de poblamiento, las selvas desaparecen y se levantan nuevos pueblos, por lo que a la literatura le compete la misión de acompañar y enriquecer el proceso, desflorando en términos simbólicos a las recientes ganancias del ecúmene. El tropo de la virginidad alienta también las incitaciones que Donoso lanza ya en 1912, cuando los escritores disponen -en los extramuros metropolitanos- de una página en blanco o "un libro abierto", un "vasto campo virgen" que aguarda "la oblación fecunda de la semilla" (Donoso 1912: xxiii). Y para Melfi, hacia 1938, la disponibilidad es el sello no interrogable de unas provincias "fértiles" y hasta hace poco "abandonadas", por cuyo empleo literario debe congratularse a quienes les han dado "categoría estética" y "efectividad de dominio", acercándolas por consiguiente a los habitantes de la capital (Melfi 1938: 79).

Lo que prevalece en suma es la inclinación a suponer que el tema regional se brinda espontáneamente a la expansión descriptiva del pantónimo, y en ocasiones el ánimo ejemplificado por Melfi- de ensalzar sin ambages la labor de los autores como amanuenses de un patrón estatal centralizado. Arqueo y culminación del esfuerzo por acaparar territorios de manera mancomunada, el conjunto de atlas literarios es ya reconocible como deseo fundacional en el discurso lastarriano de 1842, donde la naturaleza con sus veneros ignotos, sus formas vírgenes y prominentes, espera aún a los genios que la exploten: "Principiad, pues, a sacar el provecho de tan pingües riquezas [...] Es el camino que debéis seguir para consumar la grande obra de hacer nuestra literatura nacional, útil y progresiva" (Lastarria 1968: 105-106). Habrá esbozos de atlas con antelación a su hiperactiva comparecencia en los cuarenta, y los habrá igualmente al avanzar la década ulterior. En su proemio a $E l$ pueblo maravilloso, de 1927, Francisco Contreras declara que este texto no es más que el inicio de un ciclo de novelas destinadas a interpretar la vida chilena, y en los cincuenta el fenómeno se alarga con obras como el Autorretrato de Guzmán o el Atlas de la poesía de Chile, en que el editor Antonio de Undurraga imputa el temperamento lírico de los oriundos a una geografía "titánica, monumental y trágica" (De Undurraga 1958: 5). Para la literatura nacionalista de aquel periodo, los espacios periféricos sólo cobran valor si califican como mónadas o sinécdoques, como enclaves y como despensas, si pueden ser cosechados como íconos representativos de la chilenidad, si pueden exhibirse, si ayudan a la expansión y si es dable extraer algo beneficioso de ellos. La lógica de visualización dominante los quiere siempre sometidos al justiprecio del espacio mayor, tal como lo sugiere cierto eco etimológico de la palabra paisaje: la raíz indoeuropea $p a k$, en el elocuente sentido de "fijar, atar, asegurar aquello que es definido por limitación de un territorio" (Castro y Copón 1997: 50). El apetito de mapeos verbales comienza a cundir en un momento caracterizado por la carencia de cartas geográficas confiables ${ }^{9}$, pero la lógica peculiar que los condiciona no podría aprehenderse

Si los levantamientos geodésicos eran muy escasos a inicios el siglo XX, como escasa era también la circulación pública de los mapas chilenos propiamente tales (Sagredo 2013: XX), cabe agregar que la Geografía 
como un destino. Su hegemonía, según se ha visto, requiere de constantes refuerzos al nivel del paratexto, a cuyos empaques se transfiere la misión de bloquear cuando menos otras tres opciones de lectura para las regiones: una lectura metafísica, genérica y no reducida a un vocabulario autóctono, como la que prosperará en años subsecuentes con la poesía de los lares; una lectura corográfica, afincada en la territorialidad inmediata, como la que insinúan algunos textos antologados por Roco; y una lectura de horizonte mundial, patrimonialista más allá de la nación, como las que propician las iniciativas contemporáneas sobre paisajes culturales.

Las enfáticas claves de interpretación que surgen de un título o de un prólogo, allí donde se materializan tanto la autoridad de los compiladores como la unidad del mensaje (Alvarado 1998: 59), inhiben sin duda las posibilidades de desgajar los fragmentos y leerlos como corografias, como universos descriptivos autosuficientes, como formas pormenorizadas y no enmarcadas de tematización, a la usanza del que contempla una nariz o una boca sin pensar en el rostro o la cabeza ${ }^{10}$. El término no es extraño a la importación de conceptos geográficos hacia los estudios literarios, y su latencia ha sido relacionada con ciertos espaciamientos indígenas $^{11}$, prenacionales, marcadamente localistas y en razón de ello invisibles para la óptica totalizadora de quien los coloniza o los ocupa desde afuera (Verdesio 1997: 147). La historicidad del modelo nacional, esa insistente dependencia del rincón respecto de Chile, se confirma también en la clase de acercamiento que ve a los espacios regionales como patrimonios probables de la humanidad, no de un país determinado, y que al menos en teoría promete conducir esos recursos paisajísticos - "huella del trabajo sobre el territorio"- teniendo como foco de los beneficios a la propia comunidad involucrada (Sabaté 2010: 12).

La perspectiva nacionalizante de los atlas pervive sin embargo hasta las inmediaciones del presente ${ }^{12}$. Además de proyectos que se originan en ámbitos ajenos a la literatura -

económica de Chile-iniciativa estrella de la Corfo- recién pudo finalizarse hacia 1962, con la publicación de sus últimos dos tomos (Arenas y Núnez, 2013: XIV).

10 Al ubicuo paratexto nacional pueden oponerse, sin ir más lejos, alternativas de adscripción regional circunscrita, con subtítulos que equivalen casi a denominaciones de origen, como "Novela maulina" (Los guanayes, de Tomás Montecino, 1946) o "Novela del sur" (Frontera, de Luis Durand, 1949).

11 Espaciamiento es el término alternativo con el que Culler explica la différance derridiana (Culler 1984: 89), y sirve también para designar tanto una ordenación preexistente como un acto de ordenar, tanto una diferencia pasiva como una simultánea diferenciación, un nuevo modelo de espacialización o un nuevo mapa. El propio Derrida utiliza el vocablo francés correspondiente: espacement. Culler lo emplea en inglés como spacing y en la versión española aparece precisamente como "espaciamiento".

12 La recurrencia de este tipo de textos podría indicar a lo menos una extensión residual del nacionalismo que Bernardo Subercaseaux (2007) plantea como fuerza cultural dominante sólo hasta 1930. El paradigma nacionalista continúa ocupándose de omitir/eliminar lo que aflora como estorbo, como lastre o, para decirlo con palabras de Parekh (2000: 96), como "focos de lealtad rivales", potencialmente capacitados para introducir diferencias en su sistema de valores. Desde tal punto de vista, la ocupación del territorio nunca puede considerarse un asunto zanjado, y precisa por ende de periódicos refuerzos, nuevos objetos en pro del reclutamiento de la sensibilidad. 
como la abultada Biblioteca Fundamentos ${ }^{13}$ - podrían nombrarse varios registros de atlas revivals, entre ellos el Memorándum chileno, de Braulio Arenas (1987), Chile espectacular, de Mauricio Wacquez (1996), y las antologías Metáforas de Chile, de Pedro Araya (1999), y Nosotros los chilenos. Autorretrato de Chile, de Pablo Azócar y otros autores. El primero es un largo poema en el que el hablante coarta de entrada y luego a cada momento la descripción no tributaria de cada pueblo y ciudad, en un recorrido norte-sur donde no hay espacio alguno que escape a la confirmación de una sola geografía (Arenas 1987: 27). Desde las capitales nortinas hasta el Estrecho de Magallanes, sólo hay matices de lo mismo, matices que el sujeto poético comenzase a conocer en un mapa de escuela y de los cuales ahora procura ser una suerte de vocero: "Fieles amigos, habitantes de Aysén, / permitid que yo asuma en este instante / una cercana voz de poesía / para hablar de vosotros" (Arenas 1987: 37). El segundo marcha también de norte a sur para referir en prosa las bondades del paisaje nacional, distinguiendo las a menudo benignas especies endémicas de las más nocivas que han llegado del exterior. Y aunque la remisión a Chile absorbe la riqueza local de los volcanes, los desiertos y los árboles, el autor no puede sino asumir que Chiloé es "un enclave ecológico cerrado y casi milagroso, asaz ajeno, natural y culturalmente, al resto del país" (Wacquez 1996: 30). La antología de Araya coge el relevo ecuménico del Autorretrato de Nicomedes Guzmán, "libro ejemplar en su empresa de reunir numerosas versiones del país que somos" (Araya 1999: 8), conformándose de este modo como una polifonía en que las distintas regiones se incorporan de acuerdo a la reflexión de sus poetas. Nosotros los chilenos, finalmente, manifiesta el ansia de refrescar las definiciones de Chile que antaño hiciesen Guzmán y los autores epónimos del criollismo, actualizando su legado por boca de lo que Raúl Zurita, Pedro Lemebel o Alejandra Costamagna pueden decir ahora sobre sus "rincones amados" (Calderón et al 2004: 5).

\section{Conclusiones}

Habida cuenta de que un libro es también un proceso multiforme de espacialización (Alvarado 1994: 18), no resulta antojadizo establecer aquí una relación analógica entre la jerarquía de sus elementos textuales -sus metrópolis, sus provincias- y el ordenamiento espacial asimismo jerárquico que comunican los atlas literarios. La analogía, no obstante, se presta a paradojas, puesto que los rangos acostumbran invertirse tanto al interior de cada nivel como al pasar del contenido a la forma. Si el discurso de los atlas se encuentra enunciado desde posiciones implícita o explícitamente metropolitanas, aunque necesitadas de una continua glorificación de su extrarradio, el modo en que dicho discurso adquiere

13 La Biblioteca Fundamentos de la Construcción de Chile es un proyecto editorial que en años recientes reeditó cien trabajos pioneros para la historia científica, técnica y profesional del país. A ese cariz científico se suman "textos clásicos del ensayo social chileno" (Estefane 2015: 353). La colección -como se lee en el paratexto editorial de uno de los volúmenes- "aspira a convertirse en un estímulo para el desarrollo nacional" (Sagredo 2013: VII). 
dimensión material hace difícil resolver qué es lo central y qué lo periférico, cuáles elementos pueden creerse decisivos y cuáles dependientes o subsidiarios. Encargado de administrar los mapeos del todo (Chile), el centro actúa en efecto desde la periferia de cada libro, desde el paratexto o, para decirlo con mayor exactitud, desde lo peritextual, como un plus informativo que sólo rodea los mensajes principales, pero que acaba modelando una lectura unitaria e impidiendo la proliferación de textos y territorios aislados. Se trata, en definitiva, de una centralidad contradictoria, aporética, a cuyos oficios queda confiada la conversión del espacio regional en territorio de Chile, y del poema o la crónica particulares en libro colectivo, ecuménico, chileno.

A través de volúmenes como el de Antonio Roco del Campo -coetáneos de los catastros del Estado-, el país aparece muchas veces como un énfasis o un ingrediente externo a las páginas de origen, por completo desprovistas de referencias a la nacionalidad. Los paratextos recurren por ende al pantónimo unificador, en torno al cual se van constituyendo las partes y los atributos. Obvio que el lector de los atlas no arranca en ese sentido desde cero, y no lo hace tampoco en lo que compete a los recorridos posibles. Desde Roco a Latorre y Nicomedes Guzmán, la nación se describe de norte a sur, de A a B, desde un Alfa hasta un Omega, como lo figurase Benjamín Subercaseaux y como se reitera en decenas de prefacios e índices. No es, en todo caso, una dominancia absoluta ni un desplazamiento inevitable. Las lateralidades que habrán de vislumbrarse en el trazado cruciforme de Blanco-amor, y en la epopeya gastronómica de Pablo de Rokha, parecen corroborar aquella tendencia a la subversión del statu quo territorial que John Brian Harley (2005: 108) considera harto más asidua en la literatura y el arte que en la historia de la cartografía. En el prólogo a una reciente investigación sobre libros anunciados y nunca publicados (es decir, en un paratexto sobre paratextos sin texto), los editores se formulan una pregunta que bien podría ser aplicada como postrera opción de lectura para los atlas y el papel que en ellos les cabe a las regiones: ¿Qué ocurre con las "partes" cuando el "todo" deja de estar disponible, cuando esa unidad mayor se transforma en una "cosa rota"? Las partes entonces - contestan los editores-, devienen propiamente "fragmentos", se vuelven "otra cosa", superan la heteronomía y se abren a la posibilidad de nuevas identidades, totalidades o articulaciones (Acero, Cáceres y Herrera 2014:12).

\section{Obras Citadas}

Acero, Nibaldo, Jorge Cáceres y Hugo Herrera, Hugo (eds.). 2014. Vestigio y especulación. Textos anunciados, inacabados y perdidos de la literatura chilena. Santiago: Chancacazo. Alvarado, Maite. 1994. Paratexto. Buenos Aires: UBA.

Araya, Pedro (ed.). 1999. Metáforas de Chile. Santiago: LOM.

Arenas, Braulio. 1987. Memorándum chileno. Santiago: La Noria.

Arenas, Federico y Andrés Núñez. 2013. "La Geografía Económica de Chile. El estudio y conocimiento del territorio y la reconstrucción y fomento de la producción del 
país”. Rafael Sagredo (ed.). Geografía económica de Chile, Tomo II. Santiago: PUC; DIBAM; Cámara Chile de la Construcción. Biblioteca Fundamentos de la Construcción de Chile. XIII-XLI

Barrios, Eduardo. 1948. Gran señor y rajadiablos. Santiago: Nascimento.

Blanco-amor, Eduardo. 1952. Chile a la vista. 1951. Santiago: Editorial del Pacífico.

Calderón, Alfonso et al. 2004. Nosotros los chilenos 10: Autorretrato de Chile. Santiago: LOM.

Castro, Fernando y Miguel Copón, M. 1997. "Paisajes en ninguna parte: tentativas sobre seis artistas americanos". Revista de Occidente 189: 49-64.

Contreras, Francisco. 2007. El pueblo maravilloso. 1927. Santiago: DIBAM; LOM.

Culler, Jonathan. 1984. Sobre la deconstrucción. Madrid: Cátedra.

De Rokha, Pablo. 1998. Epopeya de las comidas y las bebidas de Chile. 1965. Santiago: Universitaria.

De Undurraga, Antonio. 1958. Atlas de la poesía de Chile. Santiago: Universitaria.

Donoso, Armando. 1912. Los nuevos. Valencia: F. Sempere y Compañía.

Durand, Luis. 1949. Frontera. Santiago: Nascimento. 1947. Alma y cuerpo de Chile. Santiago: Nascimento. 1942. Presencia de Chile. Santiago: Nascimento.

Estefane, Andrés. 2015. "Países varios: La Biblioteca Fundamentos de la Construcción de Chile y el reconocimiento del territorio nacional”. Anales de Literatura Chilena 24: 353-370.

Falabella, Soledad. 2003. ¿Qué será de Chile en el cielo? Poema de Chile de Gabriela Mistral. Santiago: LOM.

Guzmán, Nicomedes. 1974. Autorretrato de Chile. 1957. Santiago: Zig-Zag. . 1946. "Prólogo". Juan Donoso. Tierra en celo. Santiago: Cultura. Colección La Honda. Volumen VIII. 7-10.

. 1945. "Prólogo". Mario Bahamonde. Pampa volcada. Santiago: Cultura. Colección La Honda. Volumen IV. 7-10.

Harley, John Brian. 2005. La nueva naturaleza de los mapas: ensayos sobre la historia de la cartografía. México: FCE.

Lastarria, José Victorino. 1968. Recuerdos literarios. Santiago: Zig-Zag.

Latorre, Mariano. 1983. Chile, pais de rincones. 1947. Santiago: Zig-Zag. . 1953. Autobiografía de una vocación / Algunas preguntas que no me han hecho sobre el criollismo. Santiago: AUCH.

1941. La literatura de Chile. Buenos Aires: UBA.

Mandoki, Katya. 2007. La construcción estética del estado y de la identidad nacional: prosaica III. México: Siglo XXI.

Melfi, Domingo. 1938. Estudios de literatura chilena. Santiago: Nascimento.

Méndez, Francisco. 1948. Chile: tierra y destino. Santiago: Exit.

Mistral, Gabriela. 1967. Poema de Chile. Santiago: Pomaire. . 1957. Recados contando a Chile. Santiago: Editorial del Pacífico.

Montecino, Tomás. 1946. Los guanayes. Santiago: Nascimento. 
Neruda, Pablo. 1993. Canto General. 1950. Buenos Aires: Planeta.

Núnez, Andrés. 2013. "Definiendo una geografía para la nación: la resignificación territorial de Chile, siglos XVII-XIX”. Quim Bonastra y Gerard Jori (eds.). Imaginar, organizar y controlar el territorio. Nuevas perspectivas surgidas del XII Congreso Internacional de Geocritica. Barcelona: Icaria. 167-196.

Parekh, Bhikhu. 2000. "El etnocentrismo del discurso nacionalista". A. Fernández Bravo (comp.). La invención de la nación. Lecturas de la identidad de Herder a Homi Bhabha. Buenos Aires: Manantial. 91-122.

Pimentel, Luz Aurora. 2001. El espacio en la ficción. Ficciones espaciales. La representación del espacio en los textos narrativos. Buenos Aires: Siglo XXI.

Quiroz, Rodolfo y Ángelo Narváez. 2014. "De la loca geografía de Mistral a la geografía militar de Pinochet: el periodo de la institucionalización geográfica en Chile". Revista geográfica de Valparaiso 49: 30-54.

Roco del Campo, Antonio. 1939. Panorama y color de Chile. Santiago: Ercilla.

Roger, Alain. 2007. Breve tratado del paisaje. Madrid: Biblioteca Nueva.

Sabaté, Joaquín. 2010. "De la preservación del patrimonio a la ordenación del paisaje: intervenciones en paisajes culturales de Latinoamérica”. AECID. Programa Patrimonio para el Desarrollo. Paisajes culturales: comprensión, protección y gestión. I Encuentro, Cartagena de Indias. 10-23.

Sagredo, Rafael. 2013. "La Geografía descriptiva de Enrique Espinoza: resumen de un siglo de expansión nacional". Enrique Espinoza, Geografía descriptiva de la República de Chile. Santiago: PUC; DIBAM; Cámara chilena de la construcción. Biblioteca Fundamentos de la Construcción de Chile. IX-XXIII.

Verdesio, Gustavo. 1997. "Las representaciones territoriales del Uruguay colonial: hacia una hermenéutica pluritópica”. Revista de Crítica Literaria Latinoamericana 46: 135-161.

Subercaseaux, Benjamín. 1946. Chile o una loca geografía. 1940. Santiago: Ercilla.

Subercaseaux, Bernardo. 2007. Historia de las ideas y de la cultura en Chile. Tomo IV. Nacionalismo y cultura. Santiago: Universitaria.

1993. Historia del libro en Chile (Alma y cuerpo). Santiago: Andrés Bello.

Wacquez, Mauricio. 1996. Chile espectacular. Barcelona: Lunwerg. 
